\title{
P177 BREATHLESSNESS AND LUNG FUNCTION IN OLDER WORKING ADULTS IS ASSOCIATED WITH SIGNIFICANT
} WORK DISABILITY

Joanna Szram, Susan Schofield, Annette Woods, Paul Cullinan Imperial College, London, UK

10.1136/oemed-2011-100382.391

Objectives Breathlessness and airflow limitation increase with age and are likely to result in work disability.

Methods A general population survey of adults in their sixth decade was carried out to examine the relationship between breathlessness, work performance, work disability, sickness absence and towards the end of working life. In a cross-sectional postal questionnaire survey of adults aged 51-60 across Kent ( $n=21220$, 33\% response). breathlessness was reported using a modified MRC dyspnoea score, with a number of validated measures used to assess work performance and disability. A subgroup of respondents was assessed with lung function ( $\mathrm{n}=1774)$.

Results Logistic regression showed that increased breathlessness was significantly associated with risk of poor work performance in both sexes. When analysis was adjusted for demographic, psychological and occupational factors, the relationship between breathlessness and work performance remained. Spirometry showed that men with poor work performance had a statistically significant lower mean FEV1 than those with good performance (mean (SD) 3.12L (0.75) vs 3.35L (0.62). Using spirometry data, we found that $8.9 \%$ of men and $4.3 \%$ of women had lung function that was consistent with a diagnosis of COPD; disease prevalence was markedly higher than that of reported disease (1.9\% men and $0.6 \%$ women). 
Conclusions In a large study we found a strong relationship between breathlessness and impaired work performance in older adults, likely to be due in most part to respiratory disease, the majority of it undiagnosed, as confirmed with spirometry. From a wider perspective, it seems likely that the planned increases in pension age will lead to a more disabled UK working population. 